\title{
Stille Tage in Lindau
}

Erhard Taverna

\footnotetext{
* 4th Lindau Nobel Laureate Meeting, 29.6.-4.7.2014 (www.mediatheque. lindau-nobel.org, www.lindau-nobel.org)
}

Junge Menschen schlendern durch die malerischen Gassen der Insel. Sie tragen graue Bändel mit Ausweiskarten und viele eine blaue Umhängetasche mit dem gelben Logo der 64. Tagung der Nobelpreisträger*. Eine breite Farbskala markiert die Teilnehmer, türkis für die Laureaten, die ohnehin Krawatte tragen, rot für die Gäste, gelb für die Presse, weiss für die Alumni. Das erste Treffen fand 1951, auf Anregung von zwei Ärzten, unterstützt durch Graf Bernadotte, dem Eigentümer der Insel Mainau, erstmals in Lindau statt. Jährlich steht eine Disziplin im Mittelpunkt, in diesem Sommer sind es Medizin und Physiologie. Das Treffen ist über die Jahrzehnte international geworden, die Umgangssprache ist englisch. Dieses Jahr sind 36 Nobelpreisträger gekommen, die Schweiz ist vertreten mit Werner Arber (Restriktionsenzyme), Kurt Wüthrich (Strukturaufklärung von Proteinmolekülen) und Rolf M. Zinkernagel (wie Immunzellen Virusinfekte und Tumoren erkennen). Rund 600 Nachwuchsforscher aus 77 Ländern, davon etwas mehr als die Hälfte weiblich, wurden aus Tausenden Anwärtern ausgewählt und als die besten Köpfe von der breit abgestützten Stiftung an den Bodensee eingeladen. Hier diskutieren sie während einer Woche mit ihren preisgekrönten Vorbildern, tragen Projekte vor und bahnen, nach dem Tagungsmotto educate - inspire connect, fachliche und persönliche Kontakte an.

Wissenschaftler sind Frühaufsteher. Ein frischer Wind bringt die Boote im Hafen zum Schaukeln, während die Elite fröstelnd vor dem Forum am See und dem Bayrischen Hof auf Einlass zum Science Breakfast wartet. Alle Diskussionsforen, Meisterklassen und öffentlichen Vorträge behandeln die Strukturen und Stoffwechselvorgänge der Zellorganelle. Schwerpunkte sind die Altersforschung und die personalisierte Medizin. Millionen Körperzellen kommunizieren über G-Protein-gekoppelte Rezeptoren (GPCRs). Für die Entwicklung neuer Medikamente spielen sie eine entscheidende Rolle. Statt one size fits all gilt in Zukunft eine Behandlung gemäss dem persönlichen, molekularen Profil aufgrund der individuellen Genomsequenzierung. Einmal ausgereift, so sind sich alle Redner sicher, werden die neuen, interdisziplinären Ansätze viele traditionelle, klinische Methoden ersetzen. Die breit diskutierte Entdeckung der Signalwirkungen des Stickstoffmonoxids NO und des zyklischen Guaninmonophosphats cGMP sind Beispiele für diese stille Revolution in der Medizin. Es geht auch um Karrieren und Geld. Zur Grundlagenforschung gehört die Kooperation mit der Industrie. Australien präsentiert sich am International Day als Gastland mit über drei Prozent aller welt-

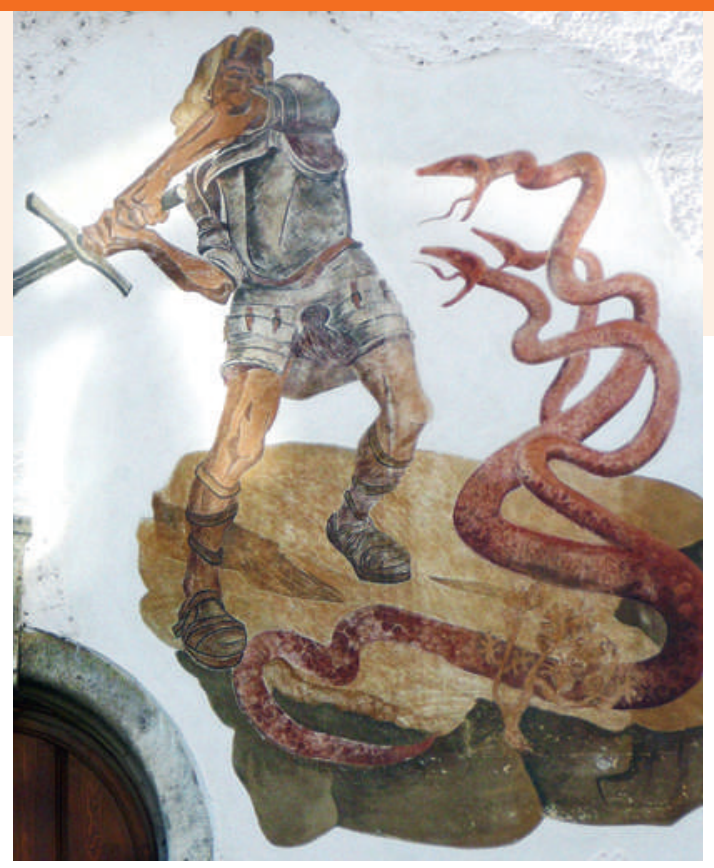

Herkules in Lindau: die Forschung im Kampf mit der Hydra.

weiten wissenschaftlichen Publikationen, als Forschungspartner, global education powerhouse und Investitionsziel für neue Technologien. Mit Barry J. Marshall ist auch ein australischer Held zugegen, der im heroischen Selbstversuch eine Ladung Helicobacter pylori verschluckte, um die ungläubige Forschergemeinde von der Infektgenese des Magenulkus zu überzeugen. «Forschung zum Wohle der Menschheit» ist in Lindau in diesen Tagen eine oft gehörte Absichtserklärung. Von 1901 bis 2013 wurde der Nobelpreis für Medizin und Physiologie 104 mal an insgesamt 204 Personen, davon 10 Frauen, vergeben. Françoise Barré-Sinoussi ist eine von ihnen. 25 Jahre nach Entdeckung des HI-Virus erhielt sie zusammen mit Luc Montaigner 2008 den Nobelpreis. Sie spricht auch zur Verantwortung des Forschers. Als Präsidentin der internationalen Aids-Gesellschaft setzt sie sich für Menschenrechte und die Eindämmung der Epidemie ein. Ihr Vortragsthema in der überfüllten Inselhalle: On the Road towards an HIV Cure.

Im Stadtmuseum sind neben der aktuellen Matisse-Ausstellung einige Räume der Tagungsgeschichte gewidmet. Erziehungsarbeit und gute Verbindungen sind ein wichtiges Anliegen der Stiftung und des Kuratoriums. Schüler sind zu Gesprächen eingeladen. Unterstützt durch den Bayrischen Rundfunk ist ein Filmarchiv aller bisherigen Tagungen online verfügbar. Die Mediathek bietet Videos, virtuelle Laborrundgänge, Vorträge, Animationen, Fotos und Zusammenfassungen an, seit neuestem auch eine Wissenschaftsgeschichte*. Was für Davos das World Economic Forum WEF ist, sind für Lindau die Tagungen der Nobelpreisträger. Weniger laut, weniger spektakulär, weniger medienwirksam, schwieriger zu vermitteln. Dafür weit wirksamer, folgenschwerer und hoffnungsvoller. Forschung ist eine Herkulesarbeit. Aus jeder Lösung wachsen neue Fragen. Die Besten waren da, hoffentlich zum vielbeschworenen benefit for mankind. 